\title{
Numerical Investigation on Vortex Structure and Aerodynamic Noise Performance of Small Axial Flow Fan
}

\author{
Li Zhang ${ }^{1,2}$, Yingzi Jin ${ }^{1 *}$ \\ ${ }^{1}$ Faculty of Mechanical Engineering \& Automation, Zhejiang Sci-Tech University, Hangzhou, China \\ ${ }^{2}$ Department of Application \& Engineering, Zhejiang Economic \& Trade Polytechnic, Hangzhou, China \\ Email: ${ }^{*}$ jin.yz@163.com
}

Received October 2, 2012; revised November 14, 2012; accepted November 23, 2012

\begin{abstract}
The details of unsteady flow field in small axial fans are described and the relationship between the internal flow characteristics and aerodynamic noise of small axial flow fans are explored in the manuscript. Firstly, the broadband noise model is introduced to calculate the distributions of broadband noise sources in fan's internal flow field, and further fan's internal flow characteristics affecting broadband noise sources are analyzed by the main distributions of broadband noise sources. Secondly, the unsteady characteristics of vortex structure in fan's internal flow field are analyzed by large eddy simulation, and FH-W acoustic model is introduced to calculate aerodynamic noise affected by the unsteady characteristics of vortex structure. Finally, monitoring points are set up near and far field of small axial fans, at which sound pressure level and spectral characteristics are analyzed. The results show that broadband noise sources are mainly distributed at the tip clearance close to blade trailing edge and one third of chord length of blade trailing edge of small axial fans. The maximum sound power of broadband noise sources at the tip clearance is greater than that at blade trailing edge. Sound power level of broadband noise near one third of blade chord length of blade trailing edge is first increasing and then decreasing when the distance between radial planes and the center of fan hub increases. Fan's internal flow characteristics affecting broadband noise sources are the tip leakage vortex and the trailing edge vortex shedding. The tip leakage vortices at the leading edge of blade tip first integrate and then break down, while vortex cores of the trailing edge vortex shedding gradually move from blade hub to one-third of blade chord length and then move to far field within a one-seventh of the rotation cycle. Within a flow passage of fan rotation period, sound pressure level of the monitoring points is relevant to the unsteady feature of vortex structure and the main bands of aerodynamic noise of monitor points are irrelevant to the unsteady feature of vortex structure, relating to the distance between the monitor points and fan. With the above distance increasing, the main bands of aerodynamic noise are widened and moved from the low bands to high bands. All conclusions in the paper will provide significant references for reducing the noise of small axial flow fans.
\end{abstract}

Keywords: Unsteady Feature; Small Axial Fan; Aerodynamic Noise; Vortex; The Internal Flow Field

\section{Introduction}

Increasing concern about noise from electrical devices has led to increasing demand for quieter cooling fans. With the increasing of small axial fans released on the market, it is difficult to judge which ones have better acoustical performance. The present study is focused on the mechanism of sound generation due to unsteady behavior of vortex flow of fan internal flow field. Actually fan's internal flow field has a great influence on aerodynamic noise [1-3]. Powell [4] proposed vortex sound theory reveal the relationship between vortex of the internal flow field and sound, and point out that sound

\footnotetext{
"Corresponding author.
}

should be produced under the conditions of existence of the vortex when the flow rate is very low. Sound was only generated in the flow field with the region of vortices changed over time. OU-yang Hua et al. [5] studied the flow field of low speed axial fans with different setting angle by PIV and CFD simulation, and analyzed the relationship between inner flow field of fan and noise radiation based on vortex sound theory of low speed homentropic flow, and then predicted aerodynamic noise of fan. It was shown that aerodynamic noise of low speed homentropic flow was mainly induced by stretch and breakdown of vortex in flow. To uniform inflow aerodynamic noise source of low speed axial fan was major caused by blade trailing edge vortex shedding and tip 
vortex noise, moreover intension of preceding noise source is highly large than the latter.

Nevertheless, few references had elaborated the vortex formation mechanism and flow characteristics of the internal flow field of small axial flow fan whose diameter is less than $200 \mathrm{~mm}$. The main distributions of aerodynamic noise sources and the effect of vortex structure on fan aerodynamic noise were still not very clear, and further study had to be carried out. The commercial FLUENT software is used in this article. The unsteady characteristics of vortex structure in fan internal flow field are analyzed by large eddy simulation. Broadband noise model is introduced to calculate the distributions of broadband noise sources in fan internal flow field, and FH-W acoustic model is introduced to calculate aerodynamic noise affected by the unsteady characteristics of vortex structure. The results will provide a useful reference about further optimizing noise characteristics of the fan.

\section{Fan Prototype}

A small axial fan RF24S9225H is selected as a study prototype in the paper, as shown in Figure 1. The impeller diameter is $84 \mathrm{~mm}$, the impeller thickness is $18 \mathrm{~mm}$, hub ratio is 0.39 , tip clearance is $1.5 \mathrm{~mm}$, number of blades is 7 , blade stagger angle is $46.9^{\circ}$, and the rated rotating speed is $3000 \mathrm{r} / \mathrm{m}$, rated air volume is $0.010 \mathrm{~kg} / \mathrm{s}$, rated air pressure is $37.25 \mathrm{~Pa}$.

\section{Mesh Generation of Computational Domain and Turbulence Model}

\subsection{Mesh and Computational Domain}

To make the air flow more fully, the arrangement of fan flow field should be reasonable. The center of fan hub is set as the coordinate origin and the length of outlet extension is $400 \mathrm{~mm}$, whose diameter in the computational domain is $200 \mathrm{~mm}$, as shown in Figure 2. Meanwhile, the computational region is divided into 4 parts, nonstructural grid (tetrahedral T-grid) is used in rotating fluid area and surrounding pipeline, while structural grid (hexahedral cooper mesh) is used in the regions of front channel and back channel, as shown in Figure 3. The total grid positions are $2.86 \times 10^{6}$ for fan prototype. The degree of twist of the grid is predominantly between 0.1 0.5 . The inlet boundary condition is set as a given flow rate, for the outlet the total pressure is taken as a boundary condition. The solid walls such as vane surfaces and hub satisfy the no-slip condition in the computational domain.

\subsection{Numerical Calculation}

The Mach number of the airflow is under 0.3 , hence, the

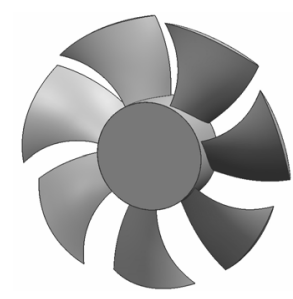

Figure 1. Fan prototype.

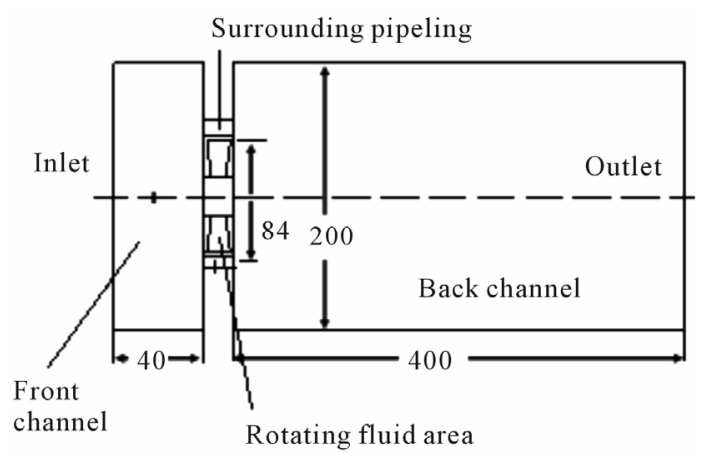

Figure 2. Computational domain.

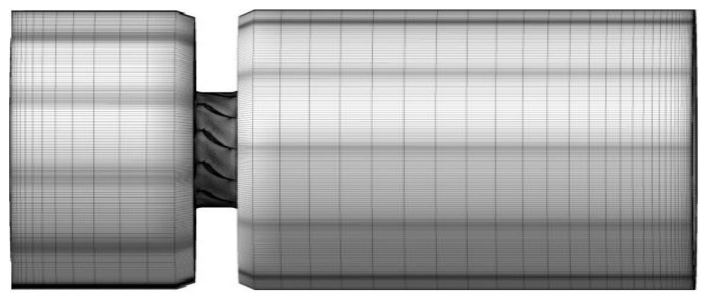

Figure 3. Mesh.

fluid is regarded as incompressible. Large eddy simulation (LES) can accurately simulate the turbulent field because it can accurately calculate not only the large scale turbulent fluctuation, but also the small scale turbulent fluctuation with the appropriately closed model [6]. In this paper, the steady flow field with standard $k-\varepsilon$ turbulence model is the initial solution to the unsteady flow field with the large eddy simulation. The filtered $\mathrm{N}-\mathrm{S}$ equations with finite volume method are adopted. S-L model with simulating sub-grid scale effects is applied and PISO algorithm to solve the coupling of velocity and pressure is used [7]. Momentum equation is calculated by the second order central difference scheme. The second order implicit scheme is used as time advance, and time step of unsteady-state calculation is set to $2 \times 10^{-5} \mathrm{~s}$.

The noise prediction can be carried out only when the statistically steady-state solution was acquired in large eddy simulation of the unsteady flow field [8]. FW-H equation based on Lighthill acoustic analogy theory is used to simulate sound production and dissemination when the noise is predicted [9]. The equation expression is: 


$$
\begin{aligned}
\frac{1}{a_{0}^{2}} \frac{\partial^{2} p^{\prime}}{\partial^{2} t}-\nabla^{2} p^{\prime}= & \frac{\partial^{2}}{\partial x_{i} \partial y_{j}}\left\{T_{i j} H(F)\right\} \\
& -\frac{\partial}{\partial x_{i}}\left\{\left[P_{i j} n_{j}+\rho u_{i}\left(u_{n}-v_{n}\right)\right] \delta(f)\right\} \\
& +\frac{\partial}{\partial t}\left\{\left[\rho_{0} v_{n}+\rho\left(v_{n}-u_{n}\right)\right] \delta(f)\right\}
\end{aligned}
$$

In the formula: $u_{i}$ is the fluid velocity component along the $x_{i}$ direction, $u_{n}$ is the fluid velocity components perpendicular to the plane $f=0, v_{i}$ is the surface velocity component along the $x_{i}$ direction, $v_{n}$ is the surface velocity components perpendicular to the plane $f=0, f=0$ is integral surface, $f<0$ is sound source zone, $f>0$ is far-field zone. $H(F)$ and $\delta(f)$ are the Heaviside function and Diracdelta function respectively:

$$
\begin{gathered}
H(F)= \begin{cases}0 & F=0 \\
1 & F \neq 0\end{cases} \\
\delta(f)=\frac{\mathrm{d}}{\mathrm{d} f}[H(F)]
\end{gathered}
$$

Noise spectrum distribution from the axial fan is acquired after the source data has been obtained in time domain integration and then fast Fourier transform (FFT) processing has been applied. Time step of noise calculation is set to $2 \times 10^{-5} \mathrm{~s}$ and cutoff frequency of noise calculation is $20 \mathrm{~Hz}$.

When the monitoring point is set up at $1 \mathrm{~m}$ away from the central axis of the impeller along fan outlet, sound pressure level of aerodynamic noise by the numerical calculation is $32.6 \mathrm{~dB}$, compared with $33 \mathrm{~dB}$ noise index of fan prototype from fan factory, and the difference is less than $1 \mathrm{~dB}$. It is proved that the numerical calculation method of fan aerodynamic noise is feasible.

\section{Results and Discussion}

\subsection{Distributions of Broadband Noise Sources}

In order to clarify the distributions of broadband noise sources in fan's internal flow field, broadband noise model is introduced after the stability of steady calculation [10]. Sound power level distributions of broadband noise in the surface of fan's flow field are calculated by broadband noise model, as shown in Figure 4. It can be seen from Figure 4 that the maximum sound power is distributed in the rotating fluid area of fan flow field. Figure 5 shows sound power level of broadband noise of meridian plane $(X=0 \mathrm{~mm})$. It can be seen from Figure 5 that sound power level of broadband noise is mainly concentrated in the rotating fluid area of fan's internal flow field, where sound power level close to the outlet is the greater than that of other regions. According to the results of Figures 4 and 5, broadband noise sources are

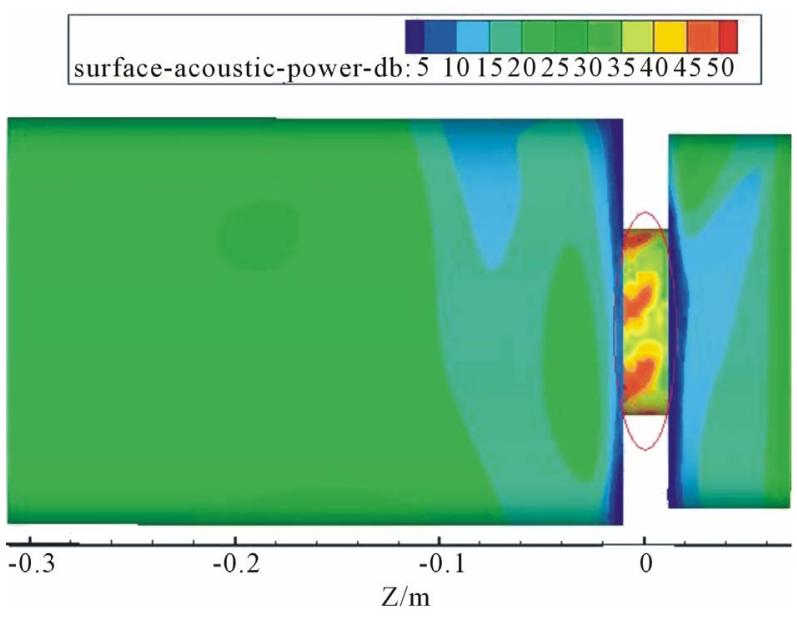

Figure 4. Sound power level distributions of broadband noise on the surface of fan's internal flow field.

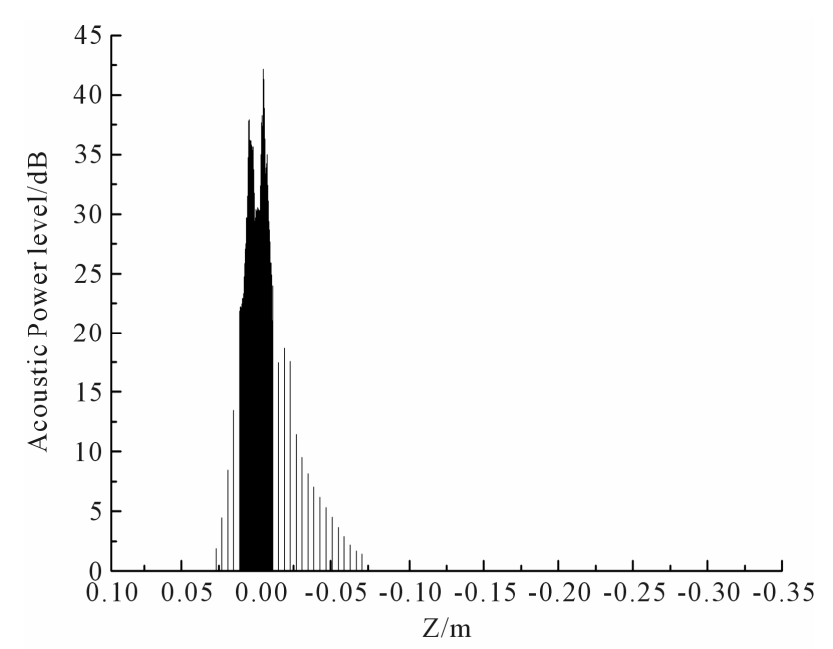

Figure 5. Sound power level of broadband noise of Meridian plane $(X=0 \mathrm{~mm})$.

mainly distributed in the rotating fluid area of fan's internal flow field.

In order to clarify the distributions of broadband noise sources in the rotating fluid area of fan's internal flow field, sound power level distributions of broadband noise of different revolution surfaces and meridian plane are analyzed respectively. Figure $\mathbf{6}$ shows sound power level contour of broadband noise of meridian plane $(Y=0$ $\mathrm{mm})$. It can be seen from Figure 6 that the maximum sound power is distributed in the tip clearance region and blade trailing edge region of the rotating fluid area and the maximum sound power at the tip clearance region is greater than that at blade trailing edge region.

Figure 7 shows sound power level contour of broadband noise of revolution surfaces $(R=24 \mathrm{~mm}$ and $R=45$ $\mathrm{mm})$. It can be seen from Figure 7(a) that the maximum sound power is distributed in blade trailing edge region, while the maximum sound power is concentrated in tip 


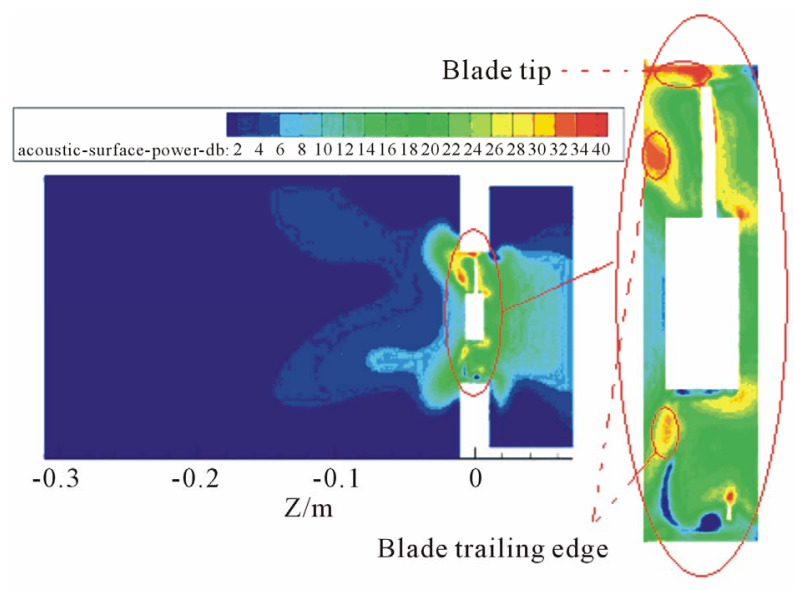

Figure 6. Sound power level contour of broadband noise of meridian plane $(Y=0 \mathrm{~mm})$.

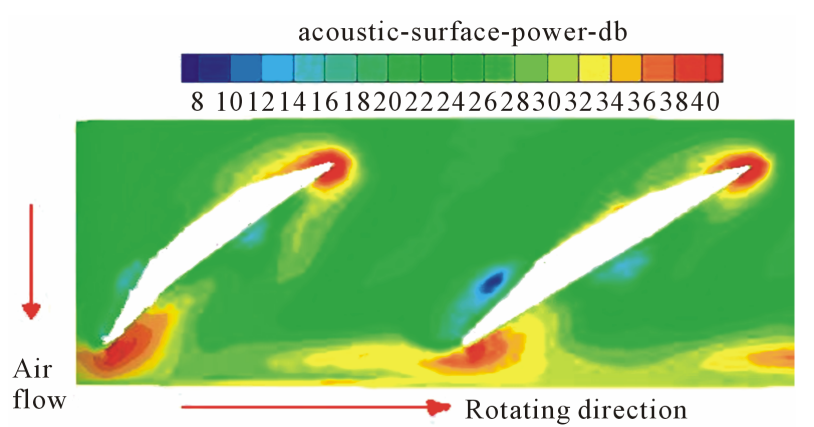

(a)

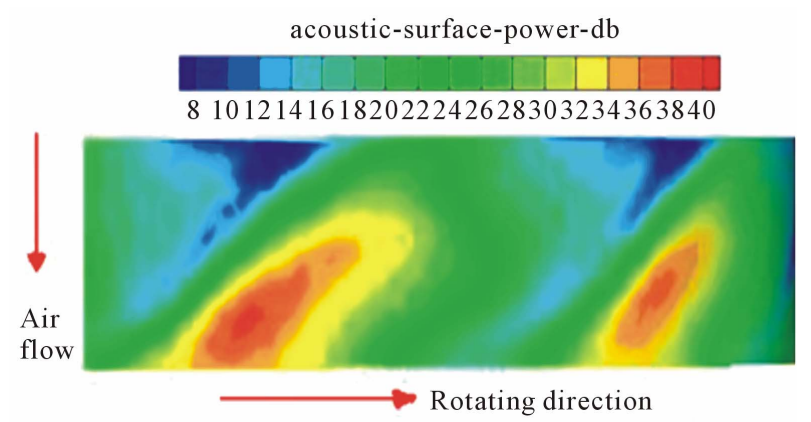

(b)

Figure 7. Sound power level contour of broadband noise of revolution surfaces. (a) $R=24 \mathrm{~mm}$; (b) $R=45 \mathrm{~mm}$.

clearance region close to blade trailing edge from Figure 7(b).

Figure 8 shows sound power level contour of broadband noise of radial planes $(Z=-8 \mathrm{~mm},-9 \mathrm{~mm}$ and -10 $\mathrm{mm})$. It can be seen from Figure 8 that the maximum sound power is distributed near radius $R=24 \mathrm{~mm}$, which means broadband noise sources in blade trailing edge region are mainly concentrated in $1 / 3$ of blade chord length. As we can see from Figures 8(a)-(c), the sound power level of broadband noise near radius $R=24 \mathrm{~mm}$ is first increasing and then decreasing when the distance

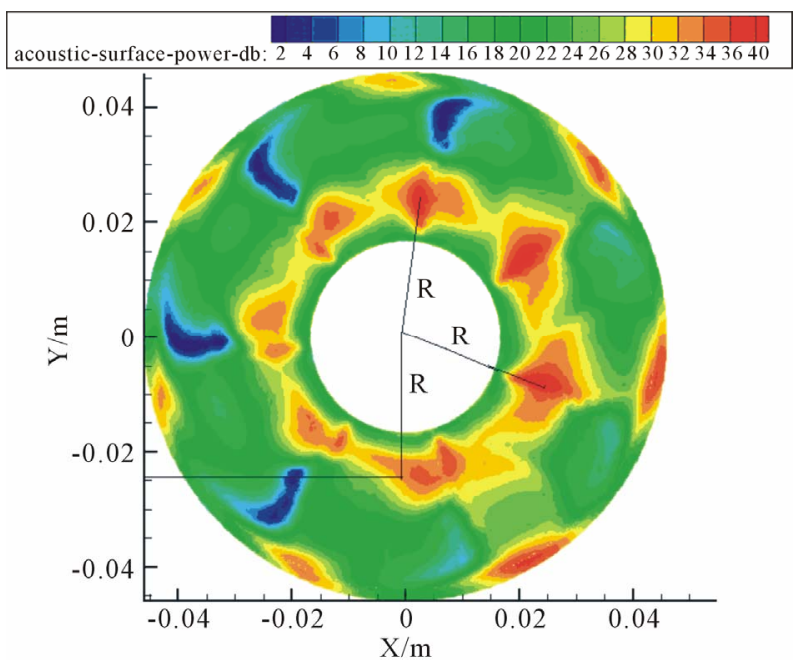

(a)

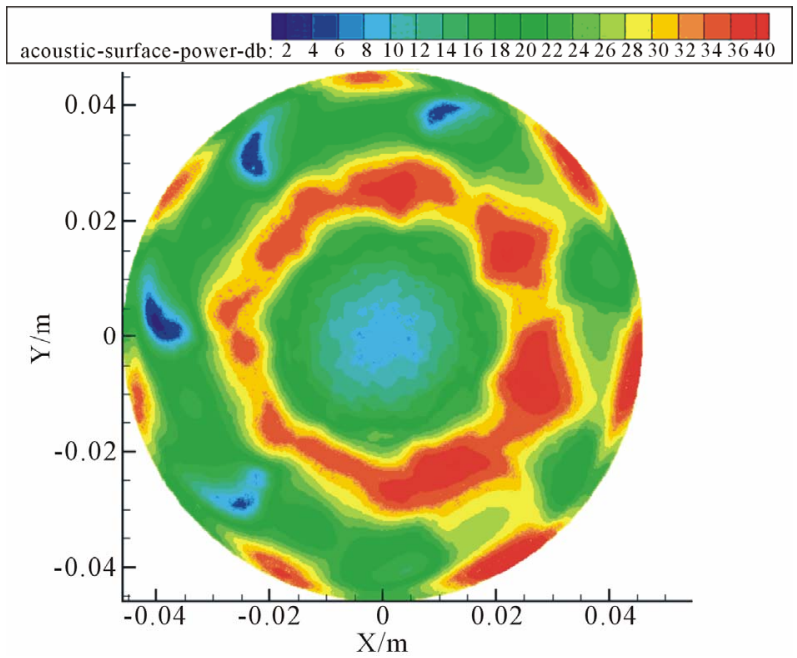

(b)

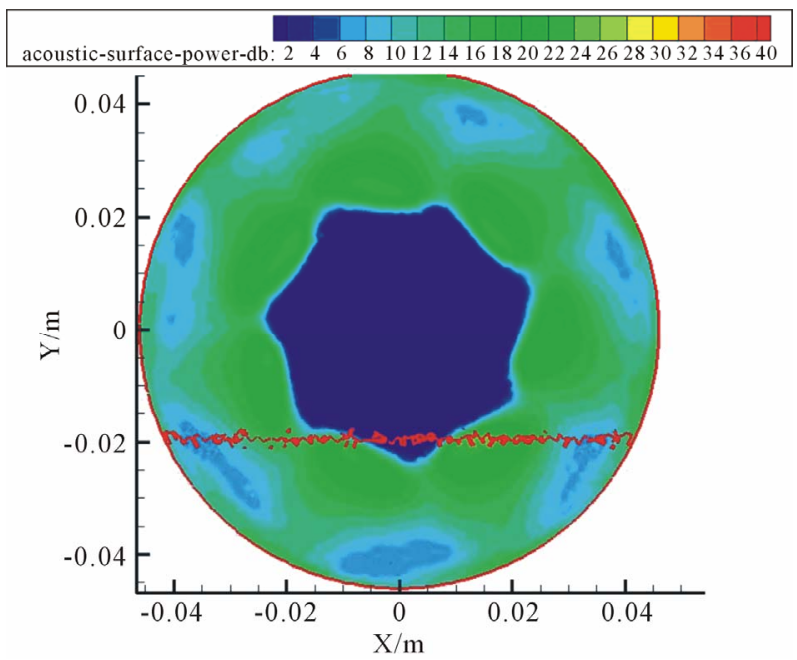

(c)

Figure 8. Sound power level contour of broadband noise of radial planes. (a) $Z=-8 \mathrm{~mm}$; (b) $Z=-9 \mathrm{~mm}$; (c) $Z=-10$ mm. 
between radial planes and the center of fan hub increases.

\subsection{Internal Flow Characteristics}

Due to the conclusions of Section 3.1 that broadband noise sources are mainly distributed in the tip clearance region and blade trailing edge region of fan rotating fluid area, the internal flow characteristics of the above regions are analyzed. Take the sections $X=0 \mathrm{~mm}$ and $X=$ $3 \mathrm{~mm}$ along the axial direction respectively, and two pieces of tip clearance regions can be obtained in the section $X=0 \mathrm{~mm}$, while a piece of blade tip clearance regions and a piece of the trailing edge regions can be obtained in the section $X=3 \mathrm{~mm}$, as shown in Figure 9.

Figure 10 shows velocity streamlines for the axial sections $X=0 \mathrm{~mm}$ and $X=3 \mathrm{~mm}$. It can be seen from Figure 10 that the tip leakage vortex is the internal flow characteristics of the tip clearance region, and blade trailing edge vortex shedding is the internal flow characteristics of blade trailing edge region.

Figure 11 shows vorticity magnitude contour for the axial section $X=3 \mathrm{~mm}$. It can be seen from Figure 11 that maximum vorticity magnitude is distributed in the tip clearance region and blade trailing edge region of the rotating fluid area. Thus the internal flow field flow characteristics affecting aerodynamic noise are the tip leakage vortex and blade trailing edge region.

\subsection{The Unsteady Characteristics of Vortex}

The unsteady characteristics of the tip leakage vortex and blade trailing edge vortex shedding are analyzed, which

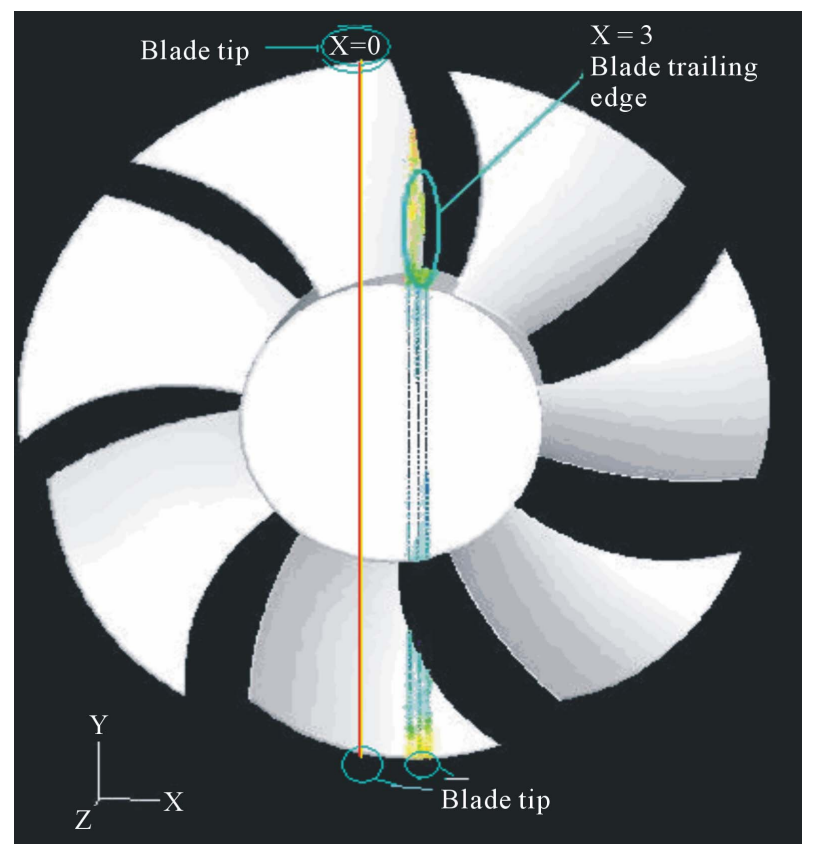

Figure 9. The sections $X=0 \mathrm{~mm}$ and $X=3 \mathrm{~mm}$ along the axial direction.

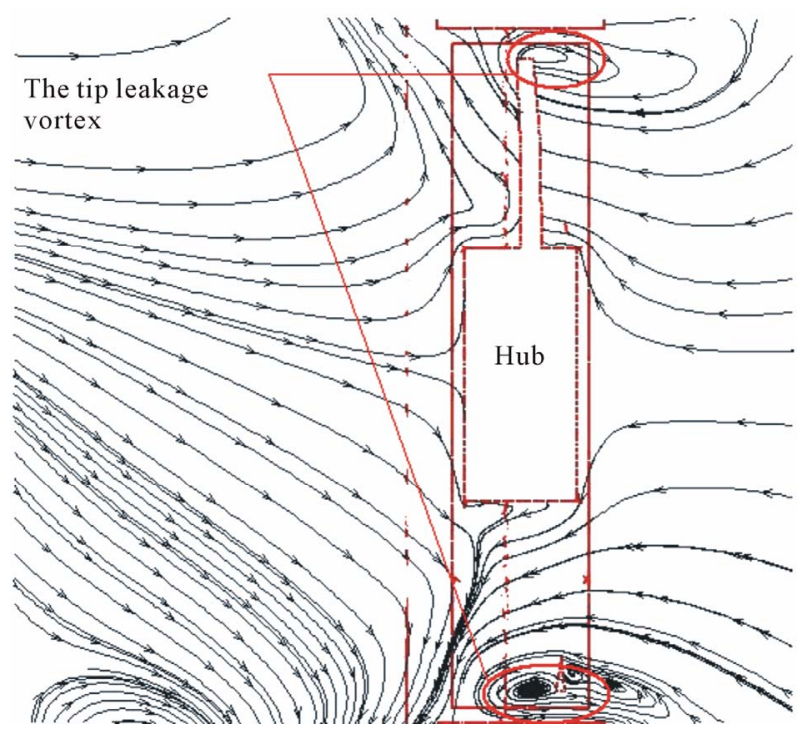

(a)

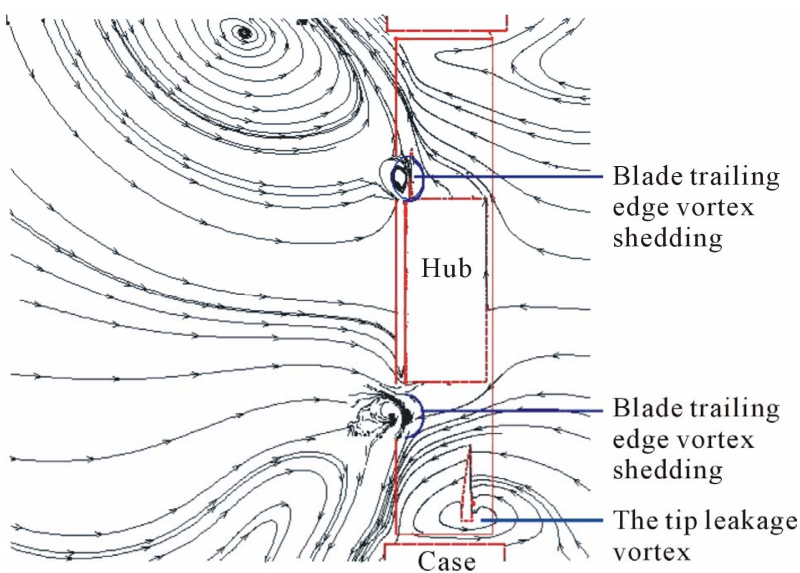

(b)

Figure 10. Velocity streamlines for the axial sections $X=0$ mm and $X=3 \mathrm{~mm}$. (a) $X=0 \mathrm{~mm}$; (b) $X=3 \mathrm{~mm}$.

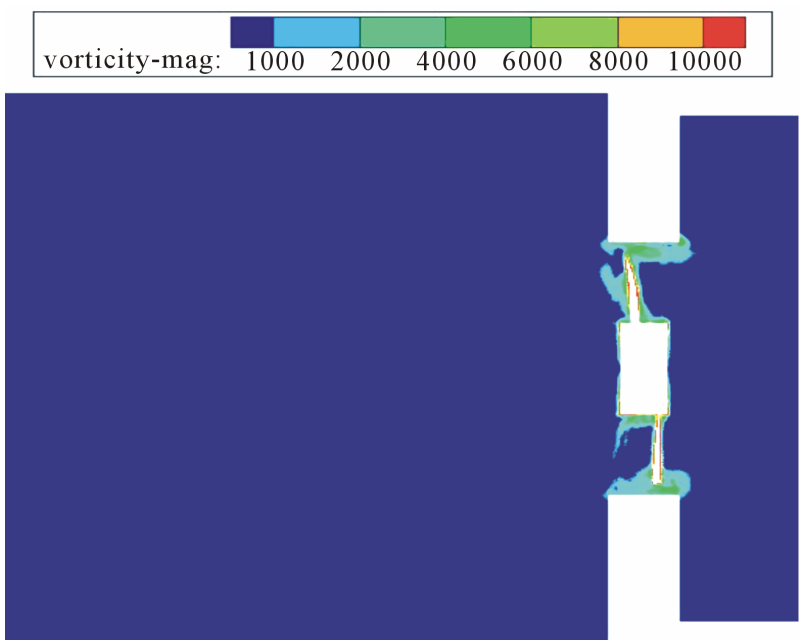

Figure 11. Vorticity magnitude contour for the axial section $X=3 \mathbf{m m}$. 
contributes to describing the viscous flow details and variation patterns of the internal flow characteristics. As blade number of fan is 7 and it is the axial symmetrical structures, so the unsteady characteristics of the vortices are only analyzed in $1 / 7$ of the rotation cycle. Due to a rotation period $T=0.02 \mathrm{~s}$, velocity streamlines of 5 different moments are sampled within the one-seventh rotation cycle respectively $(t=0.018648 \mathrm{~s}, t=0.018688 \mathrm{~s}$, $t=0.018728 \mathrm{~s}, t=0.018768 \mathrm{~s}, t=0.018788 \mathrm{~s})$. Figure 12 shows velocity streamlines at different times within a one-seventh of the rotation cycle.

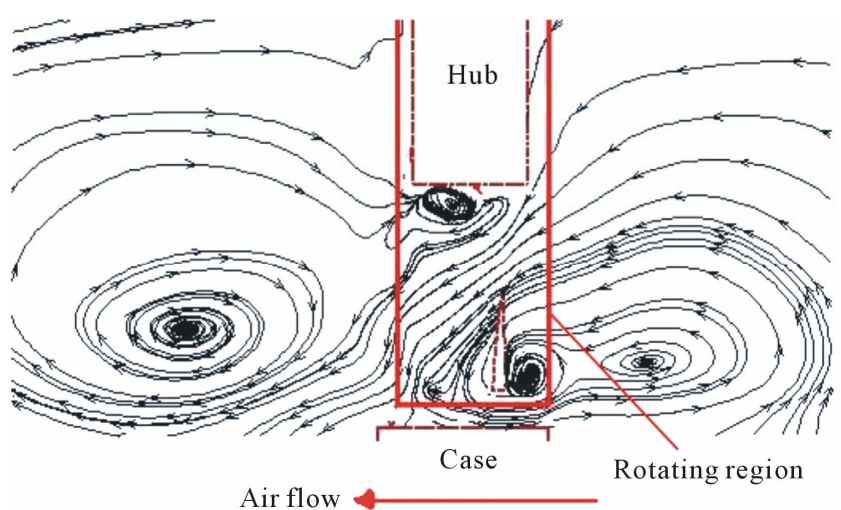

(a)

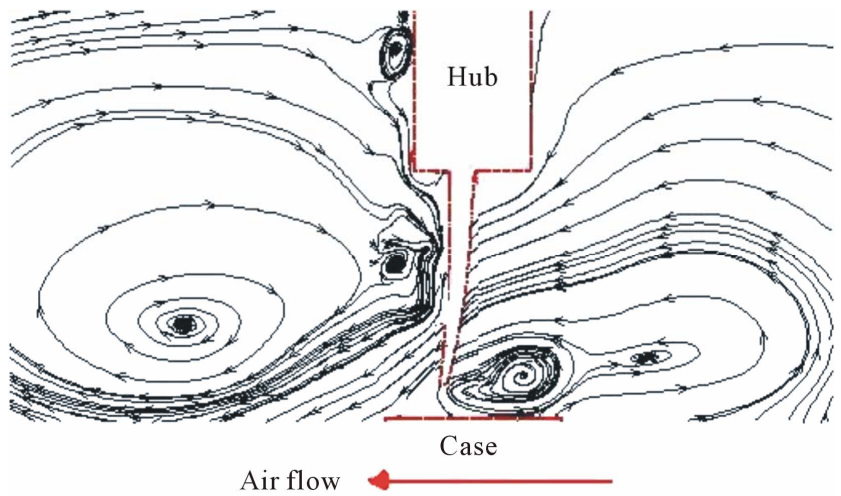

(c)
It can be seen from Figure 12 that the tip leakage vortices at the leading edge of blade tip are integrated from $t=0.018648 \mathrm{~s}$ to $t=0.018768 \mathrm{~s}$, and the number of vortex cores gradually decrease from 2 to 1 . The vortex energy of blade tip is gradually enhanced during this time. However, the tip leakage vortices are broken down from $t=0.018768 \mathrm{~s}$ to $t=0.018788 \mathrm{~s}$, and the number of vortex cores gradually increase from 1 to 2 . The vortex energy of blade tip is gradually weakened during this time. Vortex cores of blade trailing edge vortices gradually move from blade hub to one-third of blade chord length

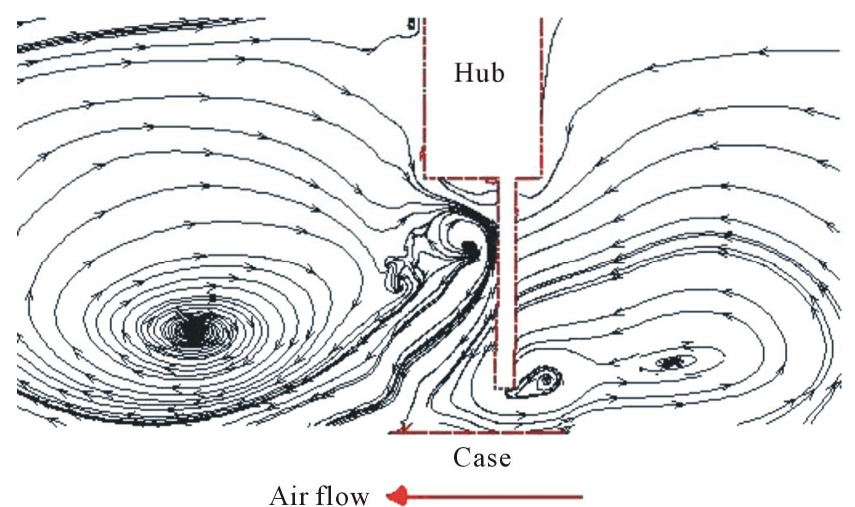

(b)

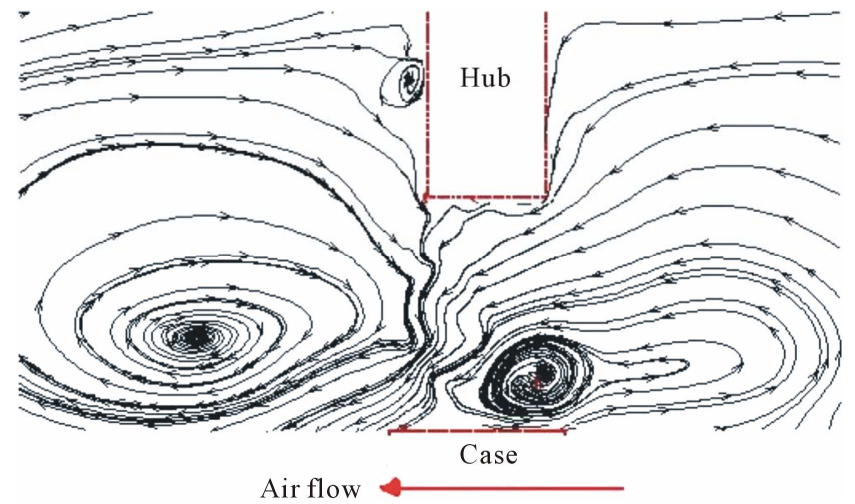

(d)

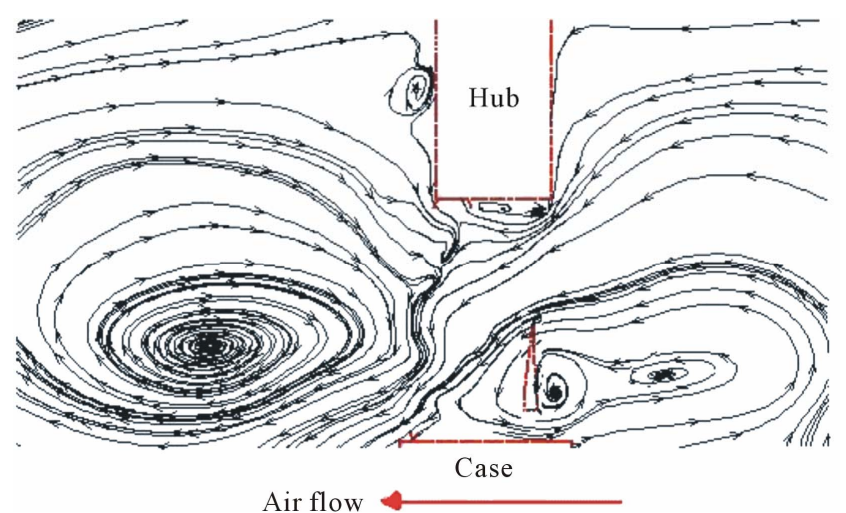

(e)

Figure 12. Velocity streamlines at different times within a one-seventh of the rotation cycle. (a) $t=0.018648 \mathrm{~s} ;(\mathrm{b}) t=0.018688$ $\mathrm{s} ;$ (c) $t=0.018728 \mathrm{~s}$; (d) $t=0.018768 \mathrm{~s}$; (e) $t=0.018788 \mathrm{~s}$. 


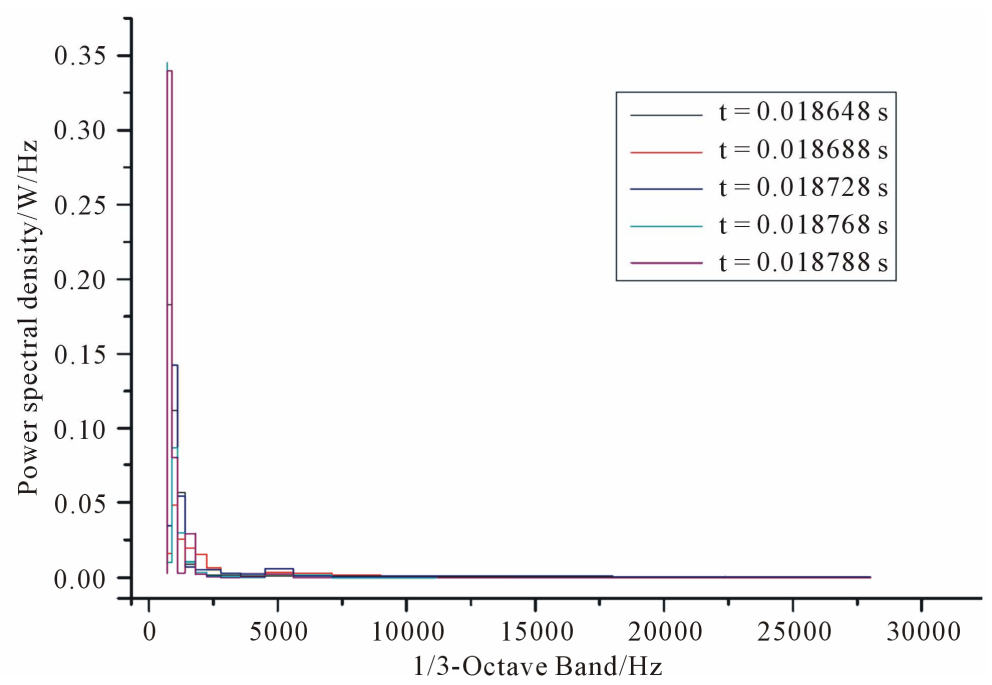

(a)

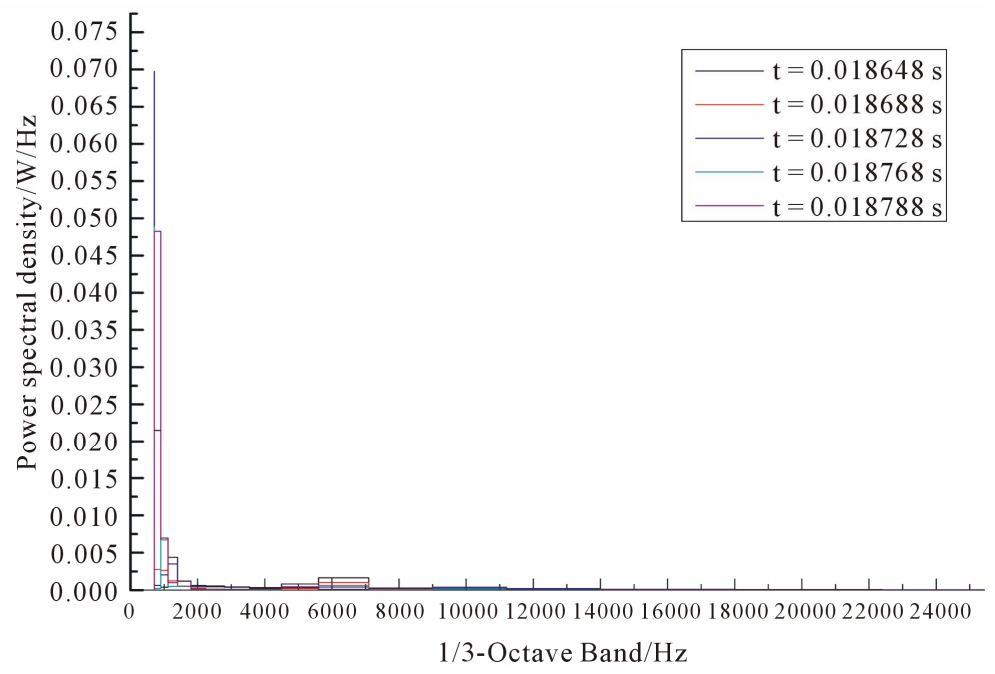

(b)

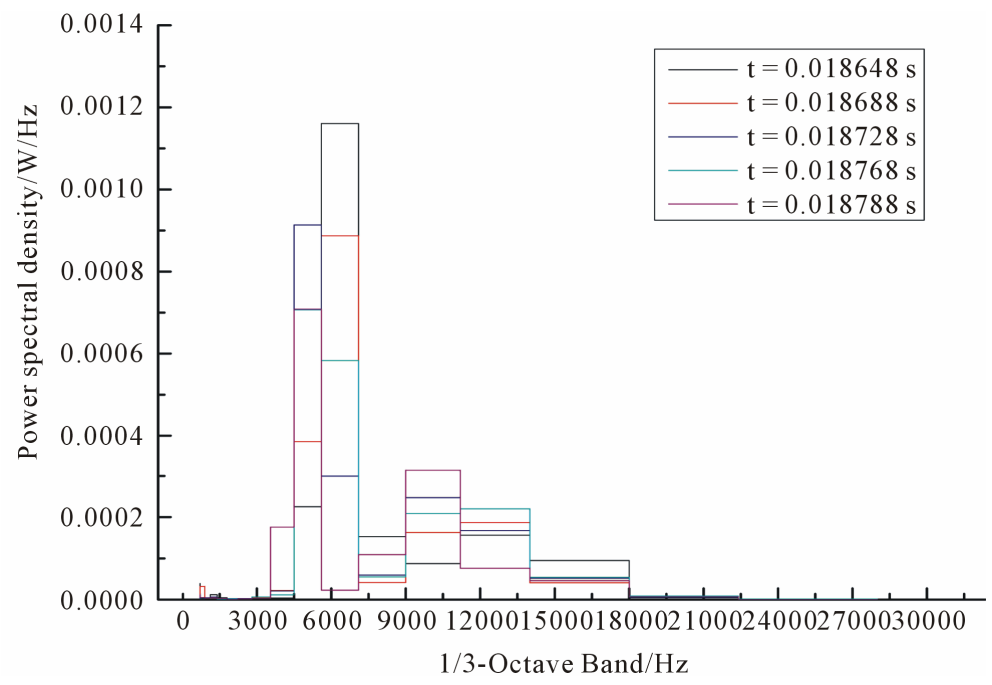

(c)

Figure 13. Power spectral density distributions of monitoring points. (a) Monitoring point 1; (b) Monitoring point 2; (c) Monitoring point 3. 
Table 1. Sound pressure level of aerodynamic noise of monitoring points at different time.

\begin{tabular}{cccccc}
\hline Sample time Monitoring points & $t=0.018648 \mathrm{~s}$ & $t=0.018688 \mathrm{~s}$ & $t=0.018728 \mathrm{~s}$ & $t=0.018768 \mathrm{~s}$ & $t=0.018788 \mathrm{~s}$ \\
\hline Monitoring point 1 coordinate $(0,24,-8)$ & $99.11 \mathrm{~dB}$ & $98.60 \mathrm{~dB}$ & $98.54 \mathrm{~dB}$ & $98.50 \mathrm{~dB}$ & $98.49 \mathrm{~dB}$ \\
Monitoring point 2 coordinate $(0,45,-9)$ & $88.76 \mathrm{~dB}$ & $90.16 \mathrm{~dB}$ & $90.61 \mathrm{~dB}$ & $90.93 \mathrm{~dB}$ & $89.90 \mathrm{~dB}$ \\
Monitoring point 3 coordinate $(0,0,-100)$ & $68.51 \mathrm{~dB}$ & $67.98 \mathrm{~dB}$ & $67.66 \mathrm{~dB}$ & $67.00 \mathrm{~dB}$ & $66.86 \mathrm{~dB}$ \\
\hline
\end{tabular}

and then move to far field from $t=0.018648 \mathrm{~s}$ to $t=$ $0.018788 \mathrm{~s}$. The vortex energy of blade trailing edge is gradually weakened during this time.

\subsection{Vortex and Aerodynamic Noise}

It is necessary to clarify aerodynamic noise caused by the unsteady flow of vortices. Monitoring points are set up at $1 / 3$ of blade chord length of blade trailing edge, blade tip near blade trailing edge and fan outlet extension, which are named monitoring point 1 , monitoring point 2 and monitoring point 3 respectively. $\mathrm{FH}-\mathrm{W}$ acoustic model is introduced to calculate aerodynamic noise of monitoring points at different time, as shown in Table 1. It can be seen from Table 1 that sound pressure level is reduced from $t=0.018648 \mathrm{~s}$ to $t=0.018788 \mathrm{~s}$ at monitoring point 1 , which is consistent with the variation of vortex energy of blade trailing edge vortex shedding during this time. Since monitoring point 1 is set up at the main distribution region of blade trailing edge vortex shedding, aerodynamic noise of monitoring point 1 can be considered relating to blade trailing edge vortex shedding. And so on, aerodynamic noise of monitoring point 2 can be considered relating to the tip leakage vortex.

Figure 13 shows power spectral density distributions of monitoring point 1 , monitoring point 2 as well as monitoring point 3 in the different moments. It can be seen from the figure that sound pressure level of monitoring points is relevant to different sample time and the main bands of aerodynamic noise of monitoring points are irrelevant to different sample time, relating to the distance between the monitoring points and fan. With the above distance increasing, the main bands of aerodynamic noise are widened and moved from the low bands to high bands. Since the unsteady feature of vortex structure is related to different sample time, sound pressure level of the monitoring points is relevant to the unsteady feature of vortex structure and the main bands of aerodynamic noise of monitor points are irrelevant to the unsteady feature of vortex structure according to Figures 12 and 13.

\section{Conclusions}

The internal flow field of small axial fans has a great influence on aerodynamic noise. The relationship between the internal flow characteristics and aerodynamic noise of small axial fans is analyzed through the introduction of broadband noise model and the FW-H model. The following conclusions are drawn:

1) Broadband noise sources are mainly distributed at the tip clearance close to blade trailing edge and onethird of chord length of blade trailing edge of small axial fans.

2) The maximum sound power of broadband noise sources at the tip clearance is greater than that at blade trailing edge. Sound power level of broadband noise near one-third of blade chord length of blade trailing edge is first increasing and then decreasing when the distance between radial planes and the center of fan hub increases.

3) Fan internal flow characteristics affecting broadband noise sources were the tip leakage vortex and the trailing edge vortex shedding. The tip leakage vortices at the leading edge of blade tip first integrate and then break down, while vortex cores of the trailing edge vortex shedding gradually move from blade hub to one-third of blade chord length and then move to far field within a one-seventh of the rotation cycle.

4) Within a flow passage of fan rotation period, sound pressure level of the monitoring points is relevant to the unsteady feature of vortex structure and the main bands of aerodynamic noise of monitor points are irrelevant to the unsteady feature of vortex structure, relating to the distance between the monitor points and fan. With the above distance increasing, the main bands of aerodynamic noise are widened and moved from the low bands to high bands.

\section{Acknowledgements}

This work was supported by grants from Major Special Project of Technology Office in Zhejiang Province (No. 2011C16038, No. 2011C11073) and from the National Natural Science Foundation of China (No. 51006090).

\section{REFERENCES}

[1] S. Velarde, T. Ballesteros and C. Hurtado, "Experimental Determination of the Tonal Noise Sources in a Centrifugal Fan," Journal of Sound and Vibration, Vol. 295, No. 35, 2006, pp. 781-796. doi:10.1016/j.jsv.2006.01.049

[2] D. A. Quinlan, "High Frequency Noise Generation in Small Axial Flow Fans," Journal of Sound and Vibration, Vol. 218, No. 2, 1998, pp. 177-204. 
doi:10.1006/jsvi.1998.1681

[3] M. S. Howe, "Sound Generated by Fluid-Structure Interactions," Computer \& Structures, Vol. 5, No. 3, 1997, pp. 145-152.

[4] A. Powell, "Theory of Vortex Sound," Journal of the Acoustical Society of America, Vol. 36, No. 1, 1964, pp. 177-195. doi:10.1121/1.1918931

[5] Y. H. Ou, J. Tian, et al., "Research of Aerodynamic Noise Source of Low Speed Axial Fans Based on Vortex Sound Theory," Journal of Engineering Thermophysics, Vol. 20, No. 5, 2009, pp. 765-768.

[6] G. X. Cui, C. X. Xu and Z. S. Zhang, "Progress in Large Eddy Simulation of Turbulent Flows," Acta Aerodynamica Sinica, Vol. 22, No. 2, 2004, pp. 121-129.

[7] E. Roland, "Broadband Slat Noise Prediction Based on
CAA and Stochastic Sound Source from a Fast Random Particle-Mesh (RPM) Method," Computers \& Fluids, Vol. 37, No. 4, 2008, pp. 369-387. doi:10.1016/j.compfluid.2007.02.003

[8] Q. G. Chen, L. J. Li and W. B. Wang, "Large Eddy Simulation of the Discrete Noise in an Axial-Flow Fan," Fluid Machinery, Vol. 38, No. 2, 2010, pp. 18-22.

[9] J. E. F. Williams and D. L. Hawkings, "Sound Generated by Turbulence and Surfaces in Arbitrary Motion," Philosophical Transactions of the Royal Society, Vol. 264, No. 11, 1969, pp. 321-342. doi:10.1098/rsta.1969.0031

[10] A. E. Filios, N. S. Tachos, A. P. Fragias, et al., "Broadband Noise Radiation Analysis for an HAWT Rotor," Renewable Energy, Vol. 32, No. 9, 2007, pp. 1497-1510. doi:10.1016/j.renene.2006.10.002 